\title{
Perioperative risk stratification in non cardiac surgery: role of pharmacological stress echocardiography Rosa Sicari*
}

\author{
Address: CNR Institute of Clinical Physiology, Via G. Moruzzi, 156124 Pisa, Italy \\ Email: Rosa Sicari* - rosas@ifc.cnr.it \\ * Corresponding author
}

This article is available from: http://www.cardiovascularultrasound.com/content/2/l/4

(C) 2004 Sicari; licensee BioMed Central Ltd. This is an Open Access article: verbatim copying and redistribution of this article are permitted in all media for any purpose, provided this notice is preserved along with the article's original URL.

\begin{abstract}
Perioperative ischemia is a frequent event in patients undergoing major non-cardiac vascular or general surgery. This is in agreement with clinical, pathophysiological, and epidemiological evidence and constitutes an additional diagnostic therapeutic factor in the assessment of these patients. Form a clinical standpoint, it is well known that multidistrict disease, especially at the coronary level, is a severe aggravation of the operative risk. From a pathophysiological point of view, however, surgery creates conditions able to unmask coronary artery disease. Prolonged hypotension, hemorrhages, and haemodynamic stresses caused by aortic clamping and unclamping during major vascular surgery are the most relevant factors endangering the coronary circulation with critical stenoses. From the epidemiological standpoint, coronary disease is known to be the leading cause of perioperative mortality and morbidity following vascular and general surgery: The diagnostic therapeutic corollary of these considerations is that coronary artery disease - and therefore the perioperative risk - in these patients has to be identified in an effective way preoperatively.
\end{abstract}

\section{Background}

Risk stratification before major vascular surgery is an everyday challenge for the clinical cardiologist. The prediction of events in this set of patients bears important implications, epidemiological, clinical and practical. In fact, the size of the problem is not negligible. Cardiovascular complications account for approximately half of all mortality after non cardiac surgery and are the leading cause of death in those patients [1]. Moreover, patients with peripheral vascular artery disease have a higher chance of dying for cardiac and cardiovascular causes compared to patients with no peripheral vessel disease [2]. When both severe and symptomatic peripheral vascular disease were present, the risk of death due to coronary artery disease was 10 to 15 times higher [2]. In this set of patients the incidence of hard cardiac events (myocardial infarction and death) in the post-operative period is higher when compared to other type of non cardiac surgery. These patients are not only at risk for perioperative events, but they are also subject to late hard cardiac events.

The need of an effective risk stratification is to select patients in order to face safely the surgical procedure, by balancing the benefit of each procedure with the inherent risks. Once the aim of risk stratification is stated, i.e. the identification of patients with a high probability of experiencing a hard cardiac event, the criteria of selection have to be discussed.

\section{Risk stratification: which patients?}

The lack of controlled and randomized trials designed to assess the best strategy of stratification for patient evaluation before major vascular non cardiac surgery brought to the definition of guidelines by the American Heart 
Table I: Clinical risk stratification for nonsurgical procedures

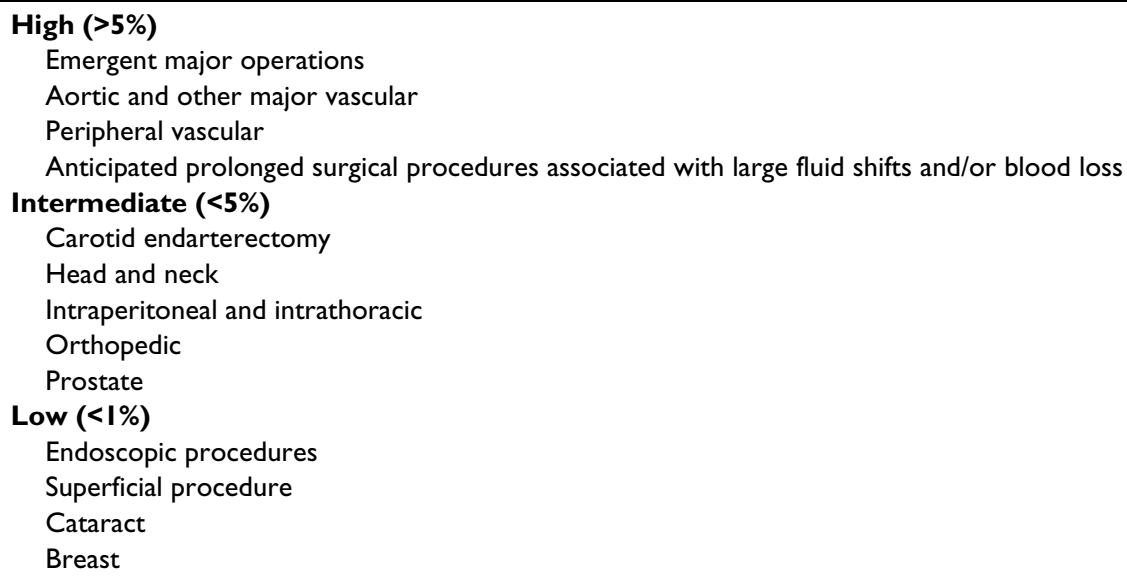

Modified from [3]

Association/American College of Cardiology [3]with the aim of: 1 - identify patients at extremely high risk in whom surgery should be canceled, or other less hazardous procedures should be considered; 2 - identify those patients in whom the optimization of medical therapy or a coronary revascularization before surgery might reduce the risk of the surgical procedure; 3 - identify those patients in whom an invasive and intensive monitoring might reduce the risk of perioperative events; 4 - assess the long-term risk of a future cardiac event. The available data of the literature show that clinical models of stratification in patients undergoing major vascular non cardiac surgery have a relatively low prognostic power $[4,5]$. Nonetheless, it is a rational approach to avoid any form of risk stratification in asymptomatic patients with no history of coronary artery disease. On the other side patients with peripheral artery disease do not have this clear clinical presentation and might experience cardiac complications due to several reasons: 1 - many of the risk factors contributing to peripheral vascular disease (diabetes mellitus, smoking habit, dyslipidemia) are also risk factors for coronary artery disease; 2 - the usual symptomatic presentation for coronary artery disease in these patients may be obscured by exercise limitations due to advanced age or intermittent claudication; 3 - major arterial operations often are time-consuming and may be associated with substantial fluctuations in intra-extra vascular fluid volumes, blood pressure, heart rate. These considerations do not imply that all patients undergoing major vascular surgery should undergo risk stratification. The decision to recommend further stratification procedures in each single patient must take into account the probability of efficacy versus the potential risks. It is conceivable that during the stratification process the risks of tests or treatment might outweigh the potential benefits of the evaluation.
Keeping in mind that the incidence of coronary artery disease in patients with peripheral vascular disease is around $60 \%$ and asymptomatic [6], preoperative screening might represent the first one for the assessment of a previously unsuspected coronary artery disease. Therefore, many patients will have their coronary artery disease diagnosed at the moment of the intervention whereas those with known coronary artery disease will benefit of an optimization of the medical regimen.

\section{Surgical risk}

In the preoperative stratification the estimate of the surgery-specific risk is a relevant one. In fact, a patient undergoing laparoscopic surgery should be treated very differently from a patient undergoing vascular surgery. Vascular surgery with its high likelihood of underlying coronary artery disease and its high degree of hemodynamic cardiac stress with profound alterations in heart rate, blood pressure, vascular volume, bleeding, clotting tendencies represent an intermediate $(1-5 \%)$ to high risk $(>5 \%)$ [3] (Table ) procedure.

\section{Risk stratification: Clinical evaluation}

The assessment of the patient's clinical status should comprise the first step of risk stratification. As already stated, literature provides a wide range of clinical models for the prediction of preoperative risk. The prototype of all models is the one developed by Goldman [4]which correlates clinical variables with post-operative cardiac events. In a multivariate analysis, nine parameters were found to be independent predictors of cardiac events. This analysis was used to develop a point system that could be used to predict risk. Progression from class I (lowest risk) to class IV (highest risk) was associated with an incremental increase in the percentage of patients with cardiac compli- 
Table 2: Clinical predictors of increased perioperative cardiovascular risk

\begin{tabular}{ll}
\hline Major & Recent myocardial infarction $(<30 \mathrm{~d})$ \\
Unstable or severe angina & Decompensated congestive heart failure \\
High-grade atrioventricular block & Symptomatic ventricular arrhythmias in the presence of underlying heart disease \\
& Supraventricular arrhythmias with uncontrolled ventricular rate \\
& Severe valvular disease \\
Intermediate & Mild angina pectoris \\
& Prior myocardial infarction by history or pathological Q waves \\
& Compensated or prior congestive heart failure \\
& Diabetes mellitus \\
Minor & Advanced age \\
Abnormal ECG & Rhythm other than sinus \\
Low functional capacity \\
History of stroke \\
Uncontrolled systemic hypertension
\end{tabular}

Modified from [3]

Table 3: Shortcut to noninvasive testing in preoperative if any two factors are present

I. Intermediate clinical predictors are present (Canadian class I or 2 angina, prior MI based on history or pathologic Q waves, compensated or prior heart failure, diabetes, or renal insufficiency)

2. Poor functional capacity (less than 4 METs)

3. High surgical risk procedure (aortic repair or peripheral vascular surgery; prolonged surgical procedures with large fluid shifts or blood loss)

cations or cardiac death. Despite successful risk stratification in a general surgical population, the Goldman study has been criticized for the lack of considerations of cardiac symptoms. To this aim Detsky et al. [5] developed a model similar to the previous but more focused on cardiac symptoms. It also differed form Goldman's model in the use of the score for a Bayesan analysis to provide a post test probability of events. The AHA/ACC guidelines identify several clinical predictors of risk, in a severity scale (Table 2), without providing a modeling of clinical stratification. Although, risk indexes have an important role in the patient's clinical evaluation, the presence of myocardial ischemia might be offset particularly in patients with peripheral vascular disease. Thus, risk classification based exclusively on clinical grounds may not prove to be as helpful when applied to vascular surgery patients [7]. AHA/ACC [3] guidelines suggest a shortcut approach to a large number of patients in whom the decision to recommend testing before surgery can be difficult (Table 3 ). Basically, if 2 of the 3 listed factors are true, the guidelines suggest the use of noninvasive cardiac testing as part of the preoperative evaluation. AHA/ACC guidelines recommend that no further cardiac evaluation is required if a recent (within 2 years) coronary angiogram failed to reveal the presence of significant obstructive coronary artery disease, or if bypass surgery was performed within the preceding 5 years, in the absence of anginal symptoms [3].

\section{Risk stratification: which test is best?}

Once, according to clinical variables, an intermediate to high risk of perioperative events is recognized for the individual patient it will be necessary to establish the presence, extent and severity of inducible myocardial ischemia, parameters which correlate with short and longterm prognosis in patients undergoing major vascular non cardiac surgery. Risk stratification with exercise electrocardiography has been performed [8-16], but this type of testing is not suitable for patients with peripheral vascular disease due to their inability to reach an ischemic threshold. Cutler et al. [9] demonstrated that patient who achieved $>75 \%$ of maximum predicted heart rate and no ischemic electrocardiographic modifications did not develop postoperative cardiac complications, whereas there were 10 postoperative cardiac events, including 7 myocardial infarctions (25\%), in the high risk group. 
Other authors [15] have confirmed these data by showing that the failure to achieve $85 \%$ of maximum predicted heart rate or 5 metabolic equivalents is a predictor of poor outcome in vascular surgery patients. These data, consistently with the AHA/ACC guidelines stress the need for an adequate functional capacity to select high risk patients. Pharmacologic stress testing with perfusion scintigraphy or ultrasound, alternative to exercise is more suitable in this set of patients due to the aforementioned physical limitations. Myocardial perfusion imaging with dipyridamole has been used widely for the preoperative evaluation of patients before vascular surgery [17-24]. The positive predictive value of thallium redistribution ranged from $4 \%$ to $20 \%$ in reports that included $>100$ patients, but more recent studies have further reduced the positive predictive value of this method, likely due to the selection of high risk patients for whom an alternative approach is followed (coronary revascularization before peripheral surgery, optimization of medical regimen etc.). The negative predictive value of a normal scan remains high at $99 \%$ for myocardial infarction and/or cardiac death. Some studies have demonstrated that not only the presence but the magnitude and severity of the perfusion abnormalities correlated with a worse outcome, suggesting that more severe defects have a greater cardiac risk $[22,23,25]$. The meta-analysis by Shaw et al. [26] analyzed the results of 10 articles describing the use of dipyridamole-thallium in vascular surgery candidates over a 9-year period (19851994). Cardiac death or nonfatal myocardial infarction occurred in 1,7 , and $9 \%$ of patients with normal results, fixed defects, and reversible defects on thallium scans, respectively. Moreover, 3 out of the 10 studies analyzed have used a semi-quantitative scoring demonstrating a higher incidence of cardiac events in patients with two or more reversible defects [26]. Recently Baron et al [27], raised the need for caution in routine screening with dipyridamole thallium stress test of all patients before vascular surgery. In this review of 457 patients undergoing elective abdominal aortic surgery, the presence of definite coronary artery disease and age greater than 65 years were better predictors of cardiac complications than perfusion imaging. In line with this evidence, Mangano [24] reassessing the use of perfusion scintigraphy, has shown its poor specificity mostly when applied to consecutive and unselected patients. In consideration of these data, some authors have stressed the need to select patients on clinical grounds first to obtain a better power of stratification when imaging techniques are used $[7,17,28]$.

Many reports have demonstrated that pharmacological stress echocardiographic imaging techniques predict perioperative ischemic events in patients undergoing noncardiac vascular surgery [29-36]. The experience of several groups with either dobutamine or dipyridamole indicates, in univocal terms, that these tests have a very high nega- tive predictive value (between 90 and 100\%): a negative test is associated with a very low incidence of cardiac events and allows a safe surgical procedure. Much lower is the positive predictive value (between 25 and $45 \%$ ). In the series by Poldermans et al. [32] the presence of a new wall motion abnormality was a powerful determinant of an increased risk for perioperative events after multivariate adjustment for different clinical and echocardiographic variables. In an update of the EPIC (Echo Persantine International Cooperative) Study - subproject risk stratification in major noncardiac vascular surgery, in a patient population of 509 [37] it has been demonstrated that test positivity identified as the variation between rest and stress wall motion score index (delta peak wall motion score) was the best predictor of peri-operative inhospital cardiac death. When the data were analyzed according to an interactive procedure, considering the variables in clinical order: historical parameters first, preoperative risk assessed on clinical grounds and stress echo parameters; still stress echocardiographic parameters added significant prediction to the model compared with historical and clinical variables. Published data, although less numerous than for perfusion scintigraphy, show that pharmacologic stress echocardiography is safe and effective in the risk stratification of this set of patients. In a meta-analysis of 15 studies [26] comparing intravenous dipyridamole-Thallium-201 imaging and dobutamine echocardiography for risk stratification before vascular surgery it has been demonstrated that the prognostic value of noninvasive stress imaging abnormalities for perioperative ischemic events is comparable between available techniques but that the accuracy varies with coronary artery disease prevalence (fig. 2). One study compares dipyridamole perfusion scintigraphy with dipyridamole stress echocardiography for the prediction of perioperative cardiac events [38]. Sensitivity of the two techniques is not significantly different (scintigraphy vs. stress echo, $90 \%$ vs. $68 \%, \mathrm{p}=\mathrm{ns}$ ), while specificity as well as diagnostic accuracy are significantly better for stress echocardiography $(88 \%$ vs. $68 \%, \mathrm{p}<0.001$ and $84 \%$ vs. $72 \%, \mathrm{p}=0.02$, respectively).

In a recent meta-analysis Kertai et al. [39] showed that pharmacologic stress echocardiography with dobutamine or dipyridamole is significantly better than perfusion scintigraphy in the prediction of perioperative events OR 37.1 (95\% CI, $8.1-170.1$ ) vs. 9.6 (95\% CI $4.9-18.4, \mathrm{P}=0.12$, dipyridamole vs. dobutamine) vs scintigraphy (OR 1.95 (95\% CI, $1.2-3.2)$. On the basis of these data stress echocardiography has a prognostic profile comparable to perfusion scintigraphy, if not better. But these considerations should be put into a wider framework in the clinical decision making. In fact, medical imaging with nuclear techniques represents the main manmade source of radiations and its environmental impact should 
be considered along with the individual risk of each single patient of experiencing a fatal or non-fatal cancer" [40]. On this issue a European Law states that a nuclear examination can be performed only when "it cannot be replaced by other techniques which do not employ ionizing radiations. This is one of those cases in which the nuclear technique can be clearly replaced without loss of critical information.

\section{Risk stratification: Instructions for use}

Once, on the basis of clinical and stress testing parameters, a patient has been recognized at high risk for future cardiac events, how to translate this information in clinical practice? In case of pharmacologic stress test negativity, because of its high negative predictive value, the surgical procedure might be undertaken safely. In case of test positivity different factors have to be taken into consideration. The stress echo response should not be read as a yes or not gate-keeper to vascular surgery. In fact, a stress echo response has different shades of severity, taking into consideration the time of appearance of the wall motion abnormalities (the shorter the time the higher the probability of an extensive coronary artery disease), the extent of wall motion abnormalities (a high number of the segments is related to an extensive disease), and the severity of the inducible dyssynergy [41]. For dobutamine stress echocardiography the need to reach the target heart rate is another critical parameter for the stratification of the stress echo response [42].

Therefore, on the basis of these parameters, it is possible to grade the response and consequently the therapeutic approach to the patient, which is different from case to case since patients with a high risk stress echo result should undergo coronary angiography and postpone cardiac surgery. Many studies have investigated the need for a coronary revascularization before a noncardiac one, but there is no study addressing this issue prospectively and evaluating the impact of a prophylactic coronary revascularization on peri-operative or long-term morbidity and mortality. Retrospective studies have demonstrated that patients undergoing coronary bypass surgery have a low rate of mortality when undergoing noncardiac surgical procedures $[43,44]$. In a sub-analysis of data from the Coronary Artery Surgery Study [43] it has been demonstrated that in 3368 patients undergoing urologic, orthopedic, breast and skin surgery the mortality rate was lower than $1 \%$ independently of a previous coronary revascularization. However, patients undergoing thoracic abdominal, vascular and head and neck surgery had a risk for death or myocardial infarction significantly higher in the first 30 days from surgery. In this set of patients undergoing high risk surgical procedures, a previous coronary revascularization reduced the incidence rate of death $(1.7 \%$ vs. $3.3 \%, p=0.03$, revascularized vs. non-revascu- larized). Therefore, in assessing the risks and benefits of perioperative intervention strategy, risks associated with non-cardiac surgery must be individualized. In selected patient populations at very high risk, coronary revascularization should be taken into consideration, weighing the potential risk reduction with the additional one associated with cardiac surgery and evaluating the long-term implications of severe forms of coronary artery disease. Percutaneous revascularization procedures are a possible, when suitable, alternative with no clear evidence of their prognostic impact. Given the limited data, the indications for PTCA in the preoperative setting are identical to those developed by AHA/ACC guidelines for the use of PTCA in general [45]. Nonetheless, this type of revascularization raise several practical problems for patient management. Stent thrombosis remains a very morbid event resulting in MI or death in the majority of patients in whom it occurs and related to the need to suspend antiplatelet treatment before surgery in order to avoid intraoperatory bleeding [46]. Therefore, It appears reasonable to delay elective non-cardiac surgery for two weeks and ideally 4 weeks to allow for at least partial endothelization of the stent, but not for more than 6 weeks or 8 weeks, when restenosis begins to occur (if it is to occur) [3].

In case of a less severe stress echo response (small extent of ischemia and/or high dose positivity), it does not seem to be necessary surgery cancellation, but a more aggressive medical approach is warranted. Recent data show, the benefit associated with the use of beta-blockers in the postoperative period. Poldermans et al. have demonstrated that bisoprolol reduces the perioperative incidence of death from cardiac causes $3.4 \%$ vs. $17 \%$; bisoprolol vs. placebo; $\mathrm{p}=0.02$ ) and nonfatal myocardial infarction ( $0 \%$ vs. $17 \%$; bisoprolol vs. placebo; $\mathrm{P}<0.001$ ) in high risk patients (dobutamine stress echocardiography positivity) undergoing major vascular surgery [47]. Subsequently, the total cohort of the study was reanalyzed, including those patients with no inducible ischemia at dobutamine stress echocardiography, showing that patients who had fewer than 3 clinical risk factors and taking beta-blockers had a lower risk of cardiac complications compared with those not taking beta-blockers $(0.8 \%$ vs. $2.3 \%$ ). In patients with 3 or more risk factors, those taking beta-blockers who had a dobutamine stress echocardiography demonstrating 4 or fewer segments of new wall motion abnormalities had a significantly lower incidence of cardiac complications $(2.3 \%$ vs $10.6 \%)$. Among patients with more extensive ischemia on dobutamine stress echocardiography (5 or more segments), beta-blocking therapy did not offer protection for cardiovascular events [48]. The protective effect of betablocking therapy is persistent in the long-term follow-up $[49,50]$. 


\section{Dipyridamole Tl-201}

Boucher 1995

Eagle 1989

Lane 1989

Younis 1989

McEnroe 1990

Mangano 1991

Hendel 1992

Baron 1994

Bry 1994

Dobutamine Echocardiography Lalka 1992

Eichelberger 1993

Langan 1993

Poldermans 1993

Davila-Roman 1993

Dipyridamole Echocardiography Tischler 1991

Rossi, 1998

Pasquet, 1998

Sicari, EPIC 1999

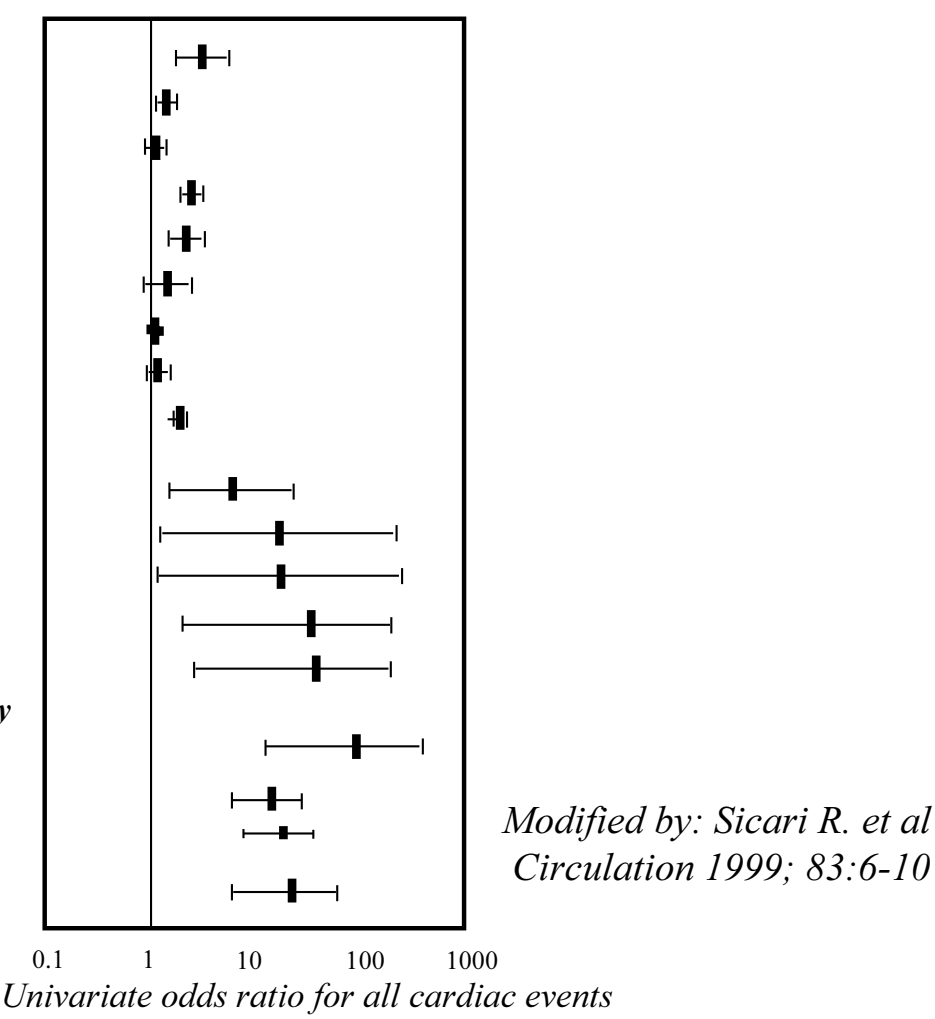

Univariate odds ratio for all cardiac events

\section{Figure I}

Univariate hazard ratio for intravenous dipyridamole-thalium-20I myocardial perfusion, dobutamine stress echocardiography and dipyridamole stress echocardiography for each of the published reports (redrawn and updated from [26]).

\section{Conclusions}

In conclusion, not all patients should undergo risk stratification. The decision to recommend further testing for the individual patient has to take into consideration the estimated probabilities of effectiveness versus risk. It is possible that in the stratification process, the risks from the tests and treatments may offset the potential benefit of evaluation. Resources should be directed away from the unnecessary investigation of low risk individuals, towards improved perioperative management for those at high risk. Pharmacologic stress echocardiography appears to be a versatile tool in this set of patients and its use is warranted. No major technical advances have been made in order to reduce the inter-observer variability of the tech- nique strictly linked to operator's experience but the search for an objective, operator-independent assessment of ischemia is on the run [51]. To date, in the absence of prospective randomized trials, it appears reasonable to perform coronary revascularization before peripheral vascular surgery, in the presence of a markedly positive result of stress echo, and reserve only for those in whom it would be considered appropriate as part of their routine long-term care, and to adopt a more conservative approach - with a watchful cardiological surveillance coupled with through pharmacological protection - in patients with less severe ischemic responses during stress [52]. 


\section{Additional material}

\section{Additional File 1}

Click here for file

[http://www.biomedcentral.com/content/supplementary/1476-

7120-2-4-S1.avi]

\section{Additional File 2}

Click here for file

[http://www.biomedcentral.com/content/supplementary/1476-

7120-2-4-S2.avi]

\section{Additional File 3}

Click here for file

[http://www.biomedcentral.com/content/supplementary/1476-

7120-2-4-S3.avi]

\section{Additional File 4}

Click here for file

[http://www.biomedcentral.com/content/supplementary/1476-

7120-2-4-S4.avi]

\section{Additional File 5}

Click here for file

[http://www.biomedcentral.com/content/supplementary/1476-

7120-2-4-S5.avi]

\section{Additional File 6}

Click here for file

[http://www.biomedcentral.com/content/supplementary/14767120-2-4-S6.avi]

\section{Additional File 7}

Click here for file

[http://www.biomedcentral.com/content/supplementary/14767120-2-4-S7.avi]

\section{Additional File 8}

Click here for file

[http://www.biomedcentral.com/content/supplementary/14767120-2-4-S8.avi]

\section{Additional File 9}

Additional file 9 movies.ppt: in the first slide is described a negative stress echo. In the left panel the images in 4 chamber view at rest, in the right panel 4 chamber view at peak stress. No change in regional function is detected. In slide 2, 3 and 4 a positive stress echo is described. In the left panel images in 4 chamber, 2 chamber and long axis view at rest are reported. No dyssynergy is present in resting conditions. In the right panels the same views are reported at peak stress. A clear apical and anterior septal dyssynergy is detectable. In slide 4 the angiographic view of the left anterior descending artery is reported in the right panel, the stenting procedure, and the angiographic result.
Click here for file

[http://www.biomedcentral.com/content/supplementary/14767120-2-4-S9.ppt]

\section{References}

I. Mangano D: Perioperative cardiac morbidity. Anesthesiology 1990, 72:153-184.

2. Criqui MH, Langer RD, Fronek A, Feigelson HS, Klauber MR, McCann TJ, Browner D: Mortality over a period of 10 years in patients with peripheral arterial disease. $N$ Engl J Med 1992, 326:38I-6.

3. Eagle KA, Berger PB, Calkins H, Chaitman BR, Ewy GA, Fleischmann KE, Fleisher LA, Froehlich JB, Gusberg RJ, Leppo JA, Ryan T, Schlant RC, Winters WL Jr, Gibbons RJ, Antman EM, Alpert JS, Faxon DP, Fuster V, Gregoratos G, Jacobs AK, Hiratzka LF, Russell RO, Smith SC Jr: ACCIAHA guideline update for perioerative cardiovascular evaluation for non cardiac surgery: a report of the American College of Cardiology/America Heart Association Task Force on Practice Guidelines (Committee to Update the 1996 Guidelines on Perioperative Cardiovascular Evaluation for Noncardiac Surgery). American College of Cardiology Web site 2002 [http://www.acc.org/clinical/guidelines/perio/update/ periupdate index.htm].

4. Goldman L, Caldera DL, Nussbaum SR, Southwick FS, Krogstad D, Murray B, Burke DS, O'Malley TA, Goroll AH, Caplan CH, Nolan J, Carabello B, Slater EE: Multifactorial index of cardiac risk in noncardiac surgical procedures. $N$ Engl J Med I977, 297:845-50.

5. Detsky AS, Abrams HB, Forbath N, Scott JG, Hilliard JR: Cardiac assessment for patients undergoing non cardiac surgery. Arch Int Med 1986, I46:2I3I-4.

6. Hertzer NR, Beven EG, Young JR, O'Hara PJ, Ruschhaupt WF 3rd, Graor RA, Dewolfe VG, Maljovec LC: Coronary artery disease in peripheral vascular patients. Ann Surg 1984, 199:223-233.

7. Eagle KA, Coley CM, Newell JB, Brewster DC, Darling RC, Strauss HW, Guiney TE, Boucher CA: Combining clinical and thallium data optimizes preoperative assessment of cardiac risk before major vascular surgery. Ann Int Med 1989, I I 0:859-866.

8. McCabe CJ, Reidy NC, Abbott WM, Fulchino DM, Brewster DC: The value of electrocardiogram monitoring during treadmill testing for peripheral vascular disease. Surgery I98I, 89:I 83-6.

9. Cutler BS, Wheeler HB, Paraskos JA, Cardullo PA: Applicability and interpretation of electrocardiographic stress testing in patients with peripheral vascular disease. Am J Surg 1981, 141:50|-6.

10. Arous EJ, Baum PL, Cutler BS: The ischemic exercise test in patients with peripheral vascular disease. Implications for management. Arch Surg 1984, I 19:780-3.

II. Gardine RL, McBride K, Greenberg H, Mulcare RJ: The value of cardiac monitoring during peripheral arterial stress testing in the surgical management of peripheral vascular disease. J Cardiovasc Surg (Torino) 1985, 26:258-61.

12. von Knorring J, Lepantalo M: Prediction of perioperative cardiac complications by electrocardiographic monitoring during treadmill exercise testing before peripheral vascular surgery. Surgery 1986, 99:610-3.

13. Leppo J, Plaja J, Gionet M, Tumolo J, Paraskos JA, Cutler BS: Noninvasive evaluation of cardiac risk before elective vascular surgery. J Am Coll Cardiol 1987, 9:269-76.

14. Hanson P, Pease M, Berkoff H, Turnipseed W, Detmer D: Arm exercise testing for coronary artery disease in patients with peripheral vascular disease. Clin Cardiol 1988, I 1:70-4.

15. McPhail N, Calvin JE, Shariatmadar A, Barber GG, Scobie TK: The use of preoperative exercise testing to predict cardiac complications after arterial reconstruction. J Vasc Surg 1988, 7:60-8.

16. Urbinati S, Di Pasquale G, Andreoli A, Lusa AM, Carini G, Grazi P, Labanti G, Passarelli P, Corbelli C, Pinelli G: Preoperative noninvasive coronary risk stratification in candidates for carotid endarterectomy. Stroke 1994, 25:2022-7.

17. Eagle KA, Singer DE, Brewster DC, Darling RC, Mulley AG, Boucher $C A$ : Dipyridamole-thallium scanning in patients undergoing vascular surgery. Optimizing preoperative evaluation of cardiac risk. JAMA 1987, 257:2 I85-9.

18. Boucher CA, Brewster DC, Darling R, Okada RD, Strauss HW, Pohost GM: Determination of cardiac risk by dipyridamole- 
thallium imaging before peripheral vascular surgery. $N$ Engl J Med 1985, 31 2:389-394

19. Leppo J, Plaja J, Gionet M, Tumulo J, Parascos JA, Cutler BS: Noninvasive evaluation of cardiac risk before elective vascular surgery. J Am Coll Cardiol 1987, 9:269-276.

20. Cutler BS, Leppo JA: Dipyridamole thallium 20 I scintigraphy to detect coronary artery disease before abdominal aortic surgery. J Vasc Surg 1987, 5:91-100.

21. Lane SE, Lewis SM, Pippin J], Kosinski EJ, Campbell D, Nesto RW, Hill $\mathrm{T}$ : Predictive value of quantitative dipyridamole-thallium scintigraphy in assessing cardiovascular risk after vascular surgery in diabetes mellitus. Am / Cardiol 1989, 64: 1275-9.

22. Hendel RC, Whitfield SS, Villegas BJ, Cutler BS, Leppo JA: Prediction of late cardiac events by dipyridamole thallium imaging in patients undergoing elective vascular surgery. $\mathrm{Am} J$ Cardiol 1992, 70:1243-9.

23. Lette J, Waters D, Cerino M, Picard M, Champagne P, Lapointe J: Preoperative coronary artery disease risk stratification based on dipyridamole imaging and simple three-step, three segment model for patients undergoing noncardiac vascular surgery. Am J Cardiol 1992, 9:1553-1558.

24. Mangano DT, London MJ, Tubau JF, Browner WS, Hollenberg M, Krupski W, Layug EL, Massie B: Dipyridamole-thallium 20 I scintigraphy as a preoperative screening test: $A$ reexaminantion of its predictive potential. Circulation 1991, 84:493-502.

25. Brown KA, Rowen M: Extent of jeopardized viable myocardium determined by myocardial perfusion imaging best predicts perioperative cardiac events in patients undergoing noncardiac surgery. J Am Coll Cardiol 1993, 21:325-330.

26. Shaw LJ, Eagle KA, Gersh BJ, Miller DD: Meta-analysis of intravenous dipyridamole-thallium-20I imaging (1985 to 1994) and dobutamine echocardiography (199 I to I994) for risk stratification before vascular surgery. J Am Coll Cardiol 1996, 27:787-98.

27. Baron JF, Mundler O, Bertrand M, Vicaut E, Barre E, Godet G, Samama CM, Coriat P, Kieffer E, Viars P: Dipyridamole-thallium scintigraphy and gated radionuclide angiography to assess cardiac risk before abdominal aortic surgery. N Engl J Med 1994, 330:663-9.

28. L'Italien G], Paul SD, Hendel RC, Leppo JA, Cohen MC, Fleisher LA, Brown KA, Zarich SW, Cambria RP, Cutler BS, Eagle KA: Development and validation of a Bayesian model for perioperative cardiac risk assessment in a cohort of $I, 08 \mathrm{I}$ vascular surgical candidates. J Am Coll Cardiol 1996, 27:779-86.

29. Lalka SG, Sawada SG, Dalsing MC, Cikrit DF, Sawchuk AP, Kovacs RL Segar DS, Ryan T, Feigenbaum H: Dobutamine stress echocardiography as a predictor of cardiac events associated with aortic surgery. I Vasc Surg 1992, I 5:83 I-42.

30. Eichelberger JP, Schwarz KQ, Black ER, Green RM, Ouriel K: Predictive value of dobutamine echocardiography just before noncardiac vascular surgery. Am J Cardiol 1993, 72:602-607.

31. Langan EM 3rd, Youkey JR, Franklin DP, Elmore JR, Costello JM, Nassef LA: Dobutamine stress echocardiography for cardiac risk assessment before aortic surgery. J Vasc Surg 1993, I 8:905-II.

32. Poldermans D, Arnese M, Fioretti PM, Salustri A, Boersma E, Thomson IR, Roelandt JR, van Urk H: Improved cardiac risk stratification in major vascular surgery with dobutamine-atropine stress echocardiography. I Am Coll Cardiol 1995, 26:648-53.

33. Davila-Roman VG, Waggoner AD, Sicard GA, Geltman EM, Schechtman KB, Perez JE: Dobutamine stress echocardiography predicts surgical outcome in patients with an aortic aneurism and peripheral vascular disease. J Am Coll Cardiol 1993, 21:957-63

34. Tischler MD, Lee TH, Hirsch AT, Lord CP, Goldman L, Creager MA, Lee RT: Prediction of major cardiac events after peripheral vascular surgery using dipyridamole echocardiography. Am J Cardiol 1991, 68:593-597.

35. Sicari R, Picano E, Lusa AM, Salustri A, Ciavatti M, Del Rosso G, et al.: The value of dipyridamole echocardiography in risk stratification before vascular surgery. A multicenter study. Eur Heart J 1995, 16:842-847.

36. Rossi E, Citterio F, Vescio MF, Pennistri F, Lombardo A, Loperfido F, Maseri A: Risk stratification of patients undergoing peripheral vascular revascularization by combined resting and dipyridamole echocardiography. Am J Cardiol 1998, 82:306-10.
37. Sicari R, Ripoli A, Picano E, Djordjevic-Dikic A, Di Giovanbattista R, Minardi G, Matskeplishvili S, Ambatiello S, Pulignano G, Accarino M, Lusa AM, Del Rosso GF, Pedrinelli R, Buziashvili $Y$, on behalf of the EPIC (Echo Persantine International Cooperative) Study Group: Perioperative Prognostic Value of Dipyridamole Echocardiography in Vascular Surgery: A Large Scale Multicenter Study on 509 Patients. Circulation 1999, 100:11269-74.

38. Pasquet A, D'Hondt AM, Verhelst R, Vanoverschelde JL, Melin J, Marwick TH: Comparison of dipyridamole stress echocardiography and perfusion scintigraphy for cardiac risk stratification in vascular surgery patients. Am J Cardiol 1998, 82: I 468-74.

39. Kertai MD, Boersma E, Sicari R, L'Italien G], Bax J], Roelandt JR, van Urk $H$, Poldermans $D$ : Which test is superior for perioperative cardiac risk stratification in patients undergoing major vascular surgery? Eur J Vasc Endovasc Surg 2002, 24:222-229.

40. Picano E: Sustainability of medical imaging. BMJ 2004, 328:578-80

4I. Picano E: Stress Echocardiography. 4th edition. Heidelberg: Springer-Verlag; 2003.

42. Marwick TH, Case C, Sawada S, Rimmerman C, Brenneman P, Kovacs $\mathrm{R}$, Short L, Lauer M: Prediction of mortality using dobutamine echocardiography. J Am Coll Cardiol 200I, 37:754-60.

43. Eagle KA, Rihal CS, Mickel MC, Holmes DR, Foster ED, Gersh BJ: Cardiac risk of noncardiac surgery: influence of coronary disease and type of surgery in 3368 operations. CASS Investigators and University of Michigan Heart Care Program. Coronary Artery Surgery Study. Circulation 1997, 96:1882-7.

44. Eagle KA, Guyton RA, Davidoff R, Ewy GA, Gardner TJ, Gott JP, et al: ACC/AHA guidelines for coronary artery bypass graft surgery: executive summary and recommendations: a report of the American College of Cardiology/American Heart Association Task Force on Practice Guidelines (Committee to Revise the 1991 Guidelines for Coronary Artery Bypass Graft Surgery). Circulation 1999, 100:|464-|488

45. Smith SC Jr, Dove JT, Jacobs AK, Kennedy JW, Kereiakes D, Kern MJ, Kuntz RE, Popma J], Schaff HV, Williams DO, Gibbons RJ, Alpert JP, Eagle KA, Faxon DP, Fuster V, Gardner T], Gregoratos G, Russell RO, Smith SC Jr: ACC/AHA guidelines for percutaneous coronary intervention: a report of the American College of Cardiology/American Heart Associations Task Force on Practice Guidelines (Committee to Revise he 1993 Guidelines for Percutaneous Transluminal Coronary Angioplasty). J Am Coll Cardiol 200I, 37:2239i-Ixvi.

46. Kaluza GL, Joseph J, Lee JR, Raizner ME, Raizner A: Catastrophic outcomes of noncardiac surgery soon after coronary stenting. J Am Coll Cardiol 2000, 35: I288-1294.

47. Poldermans D, Boersma E, Bax JJ, Thomson IR, van de Ven LL, Blankensteijn JD, Baars HF, Yo TI, Trocino G, Vigna C, Roelandt JR, van Urk $\mathrm{H}$ : The effect of bisoprolol on perioperative mortality and myocardial infarction in high-risk patients undergoing vascular surgery. Dutch Echocardiographic Cardiac Risk Evaluation Applying Stress Echocardiography Study Group. N Engl J Med 1999, 341:1789-94.

48. Boersma E, Poldermans D, Bax JJ, Steyerberg EW, Thomson IR, Banga JD, van De Ven LL, van Urk H, Roelandt JR: DECREASE Study Group (Dutch Echocardiographic Cardiac Risk Evaluation Applying Stress Echocardiogrpahy). Predictors of cardiac events after major vascular surgery: Role of clinical characteristics, dobutamine echocardiography, and beta-blocker therapy. JAMA 200I, 285: I865-73.

49. Mangano DT, Layug EL, Wallace A, Tateo I: Effect of atenolol on mortality and cardiovascular morbidity after noncardiac surgery. Multicenter Study of Perioperative Ischemia Research Group. N Engl | Med 1996, 335:17| 3-20.

50. Poldermans D, Boersma E, Bax J], Thomson IR, Paelinck B, van de Ven LL, Scheffer MG, Trocino G, Vigna C, Baars HF, van Urk H, Roelandt JR: Dutch Echocardiographic Cardiac Risk Evaluation Applying Stress Echocardiography Study Group. Bisoprolol reduces cardiac death and myocardial infarction in high-risk patients as long as 2 years after successful major vascular surgery. Eur Heart J 200I, 22:1353-8.

51. Madler CF, Payne N, Wilkenshoff U, Cohen A, Derumeaux GA, Pierard LA, Engvall J, Brodin LA, Sutherland GR, Fraser AG: Myocardial Doppler in Stress Echocardiography (MYDISE) Study Investigators. Non-invasive diagnosis of coronary artery disease by quantitative stress echocardiography: optimal diagnostic 
models using off-line tissue Doppler in the MYDISE study. Eur Heart J 2003, 24(I7): I584-94.

52. Sicari R, Ripoli A, Picano E, Pulignano G, Minardi G, Rossi E, Matskeplishvili S: Long-term prognostic value of dipyirdamole echocardiography in vascular surgery: a large scale multicenter study. Coronary Artery Disease 2002, 13:49-55.

Publish with Biomed Central and every scientist can read your work free of charge

"BioMed Central will be the most significant development for disseminating the results of biomedical research in our lifetime. " Sir Paul Nurse, Cancer Research UK

Your research papers will be:

- available free of charge to the entire biomedical community

- peer reviewed and published immediately upon acceptance

- cited in PubMed and archived on PubMed Central

- yours - you keep the copyright 